\title{
The structure of thermally reduced graphene oxide
}

\author{
Sabina Drewniak, ${ }^{* 1}$ Roksana Muzyka, ${ }^{2}$ and Łukasz Drewniak ${ }^{3}$ \\ ${ }^{1}$ Department of Optoelectronics, Faculty of Electrical Engineering, \\ Silesian University of Technology, 2 Krzywoustego Street, 44-100 Gliwice, Poland, \\ ${ }^{2}$ Institute for Chemical Processing of Coal, 1 Zamkowa Street, 41-803 Zabrze, Poland \\ ${ }^{3}$ Institute of Physics Center for Science and Education, Silesian University of Technology, \\ 22B Konarskiego Street, Gliwice, 44-100, Poland
}

Received May 15, 2020; accepted June 27, 2020; published June 30, 2020

\begin{abstract}
The paper focuses on the description of the reduced graphene oxide $(\mathrm{rGO})$ structure. This material is obtained from a multistage production process. Each stage of these stages has a large impact on the material structure (the number and type of functional groups, number of defects or size of flakes), which in turn affects its properties. We would like to visualize reduced graphene oxide, by a diagram showing its atomic structure, by imaging it with scanning electron microscopy (SEM) and by atomic force microscopy (AFM). In the paper, an elementary composition of selected elements and data obtained from the X-ray photoelectron spectroscopy technique (XPS) will be also presented.
\end{abstract}

In recent years, derivatives of graphene, especially reduced graphene oxides, have enjoyed great interest of scientists $[1 \div 3]$. These derivatives are also used as a part of hybrid structures. There are many examples like reduced graphene oxide in hybrid with gallium nitride nanorods in the systems for detection of hydrogen, noting an increase in the sensitivity of the structure after using reduced graphene oxide [4]. Reduced graphene oxide dispersion was also used to prepare a photodetector based on perovskite [5]. In this case, reduced graphene oxide is used as a channel for charge transportation (characterized by high efficiency). Yet another example, also in the field of photonics (photodetectors), is the combination of GaN, reduced graphene oxide and Ag nanoparticles [6]. Such a hybrid structure allows to obtain a broadband (NIR-VisUV) photodetector with high responsivity.

The use of reduced graphene oxide in a hybrid structure seems like a good idea, however, the choice of oxide is not so obvious and should be preceded by testing the properties of an undoped form of oxides. The source [7] states that graphene oxide is the material obtained after the exfoliation of graphite oxide to form a single sheet or several.

Our previous research [8] shows that this material is sensitive to the production method. Also in other works, the influence of preparation way on the final product is emphasized, as well as the influence of the graphite precursor $[9 \div 10]$, the oxidation method [11] and reduction

\footnotetext{
*E-mail: sabina.drewniak@polsl.pl
}

method [12]. Due to such a high sensitivity to the production method (in consequence to the properties of reduced graphene oxide), the selection of the right method of preparing rGO (which will be used in the system for a specific application) is difficult. Therefore, the characterization of selected rGOs seems necessary. One of the most important information that can be obtained during the characterization is the appearance (size, thickness, arrangement) of such material, so we used atomic force microscopy and scanning electron microscopy to achieve this goal.

Reduced graphene oxide was obtained from synthetic graphite. Next, such graphite was oxidized using: $\mathrm{H}_{2} \mathrm{SO}_{4}$ : $45 \mathrm{ml}, \mathrm{H}_{3} \mathrm{PO}_{4}: 5 \mathrm{ml}, \mathrm{KNO}_{3}$ : $1.5 \mathrm{~g}, \mathrm{KMnO}_{4}: 5 \mathrm{~g}$ (time of reaction: $5 \mathrm{~h})$. Thermal reduction was performed in the atmosphere of nitrogen $(5 \mathrm{~min})$ in $900^{\circ} \mathrm{C}$. A detailed description of the preparation method is presented in [13].

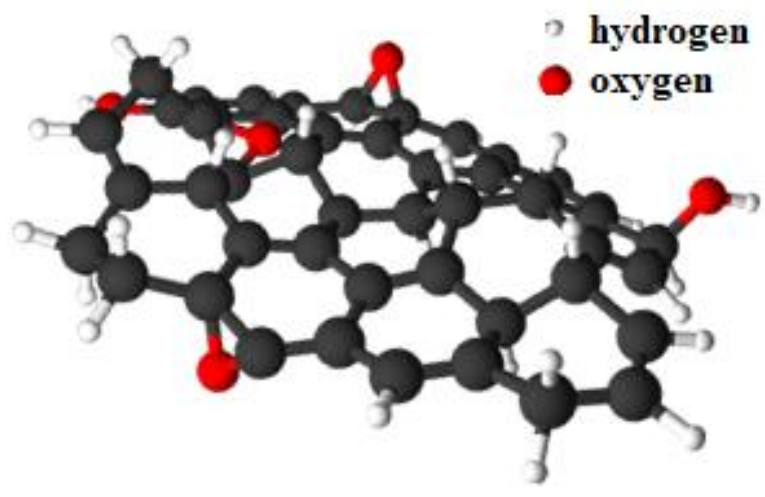

Fig. 1. An exemplary scheme of the atomic structure.

The elementary composition of reduced graphene oxide gave us information that the content of carbon, oxygen, hydrogen, nitrogen and sulfur is as follows: C: $86.6 \%$, O: $11.7 \%, \mathrm{H}: 0.8 \%, \mathrm{~N}: 0.5 \%, \mathrm{~S}: 0.4 \%$. Except for the carbon rings, hydroxyl/epoxy (12\%) and carbonyl/quinone $(5 \%)$ groups are present in the structure (based on XPS results). An exemplary scheme of atomic structure of reduced graphene oxide is shown in Fig. 1. 
The real images of the oxides were obtained using scanning electron microscopy (SEM). For this purpose, the oxides were added to ethanol and mixed by ultrasounds. Then, the mixture was placed onto a substrate with gold electrodes and dried, first at room temperature and then at $150^{\circ} \mathrm{C}$. After that, SEM imaging was performed, using an ETD and vCD detector. The images are shown in Figs. $2 \div 4$. Fig. 2 presents a part of the sample at 5000 magnification. We can see on it that the oxides form agglomerates which have a diameter of about $5 \div 15 \mu \mathrm{m}$ (there are also larger ones, $20 \div 30 \mu \mathrm{m}$, but they are much fewer).

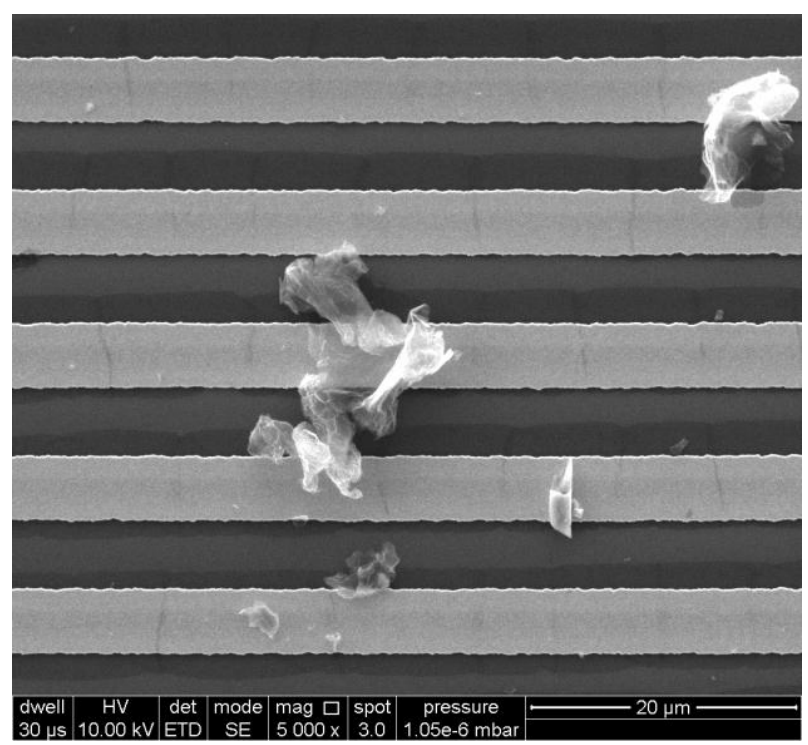

Fig. 2. SEM image of thermally reduced graphene oxide.

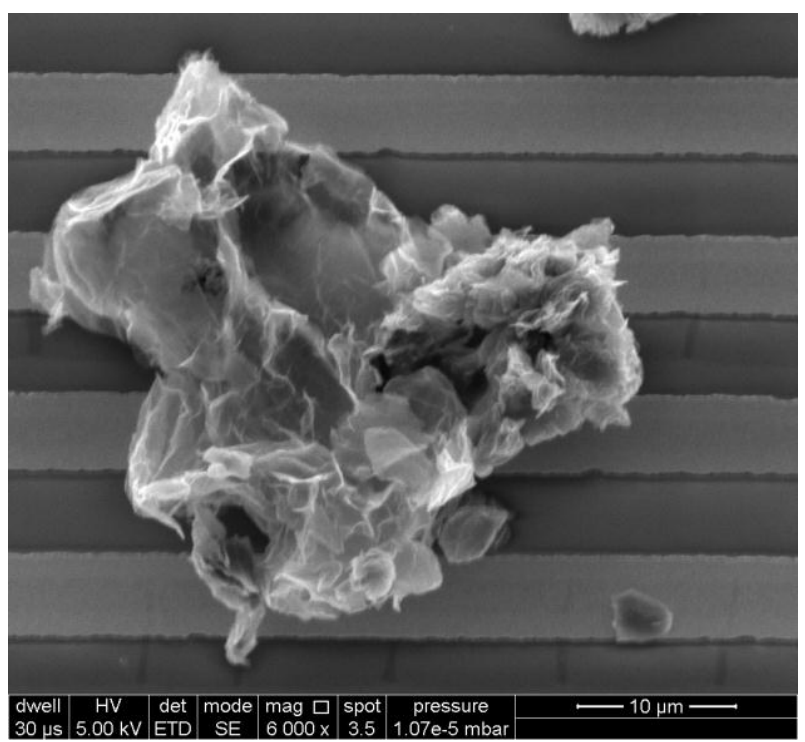

Fig. 3. SEM image of thermally reduced graphene oxide, detector: ETD. magnification was necessary. The next two images present a large agglomerate, with a diameter of about $20 \mu \mathrm{m}$.

The first of them (Fig. 3) clearly shows that the surface is wrinkled, which is important. It can be additionally noted that the surfaces of the structure do not adhere closely to each other, they are exfoliated (incompletely, heterogeneously). It could be also noticed that the smaller flakes (about $2 \mu \mathrm{m}$ ) are attached to the main flake. To confirm that these small particles are made of the same material (reduced graphene oxide) as the larger ones (that they are not accidental inclusions of other materials, e.g. dirt), an image of this area was taken using a second detector, vCD (Fig. 4). The image is homogeneous, the same color indicates that both the large flake and the smaller ones are made of materials with the same atomic numbers.

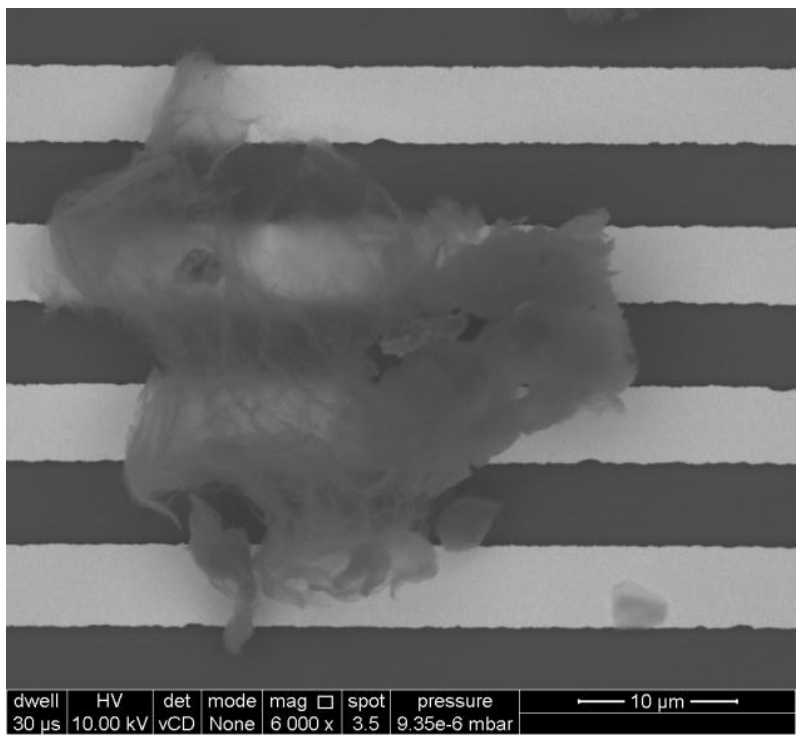

Fig. 4.SEM image of a thermally reduced graphene oxide detector: $\mathrm{vCD}$.

To look carefully at individual, delaminated flakes, additional exfoliation was needed. The applied process of preparation of reduced graphene oxide (thermal reduction) was not completed in selected conditions, about which we wrote in [8]. It means that there was no complete exfoliation of the material (total exfoliation was not our goal). The preparation of a sample for AFM tests consisted of sonication of the sample for $30 \mathrm{~min}$ in a water/DMF 1:1 mixture at a concentration of $0.3 \mathrm{mg} / \mathrm{ml}$ solution. The obtained solution was filtered through a syringe filter and immediately placed on the surface of the mica, and then dried at room temperature and next at $50^{\circ} \mathrm{C}$. Fig. 5

To better look at individual oxides, an increase in 


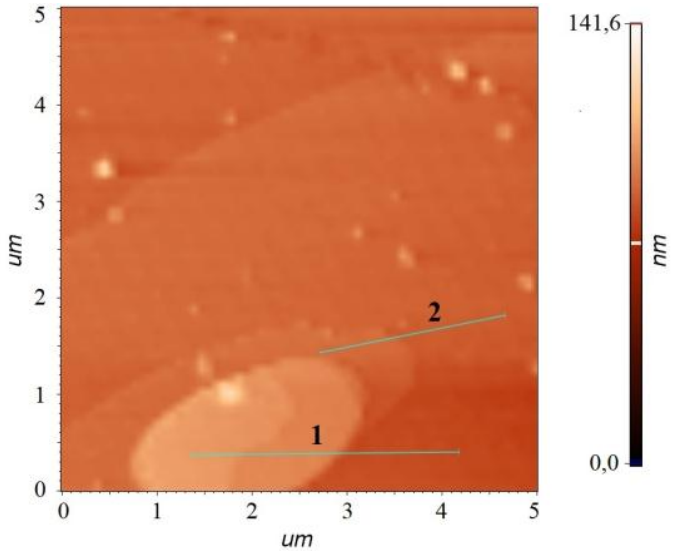

Fig. 5. An AFM image of reduced graphene oxide with the cross-section lines.

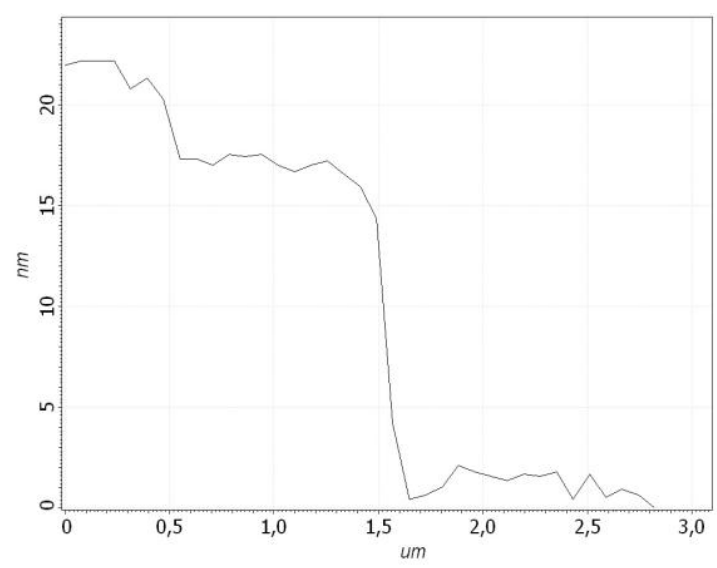

Fig. 6. The topography along the cross-section line no 1.

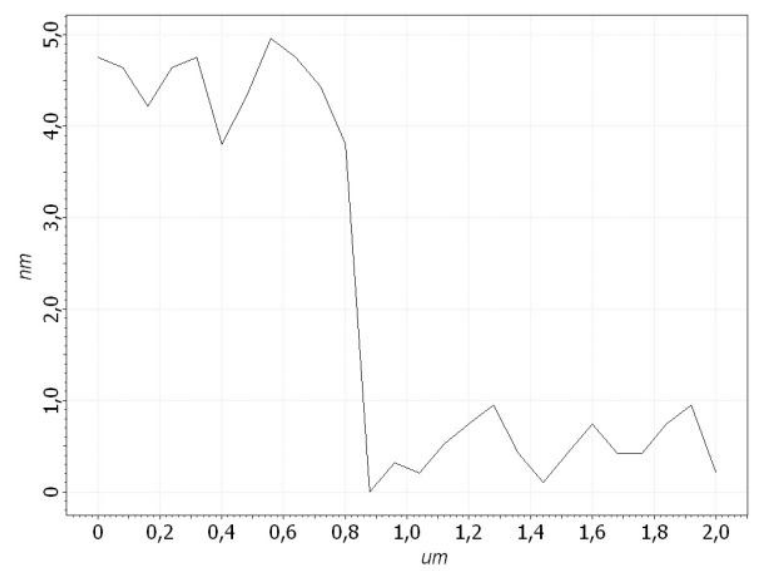

Fig. 7. The topography along the cross-section line no 2.

AFM measurements confirm that reduced graphene oxide occurs in the form of flakes of different sizes. The AFM technique allowed for determination of the height of a single flake. For this purpose, cross-sections (Fig. 6 and Fig. 7) were made through selected fragments (marked with lines in Fig. 5). Both figures show that the height of a single layer is $4-5 \mathrm{~nm}$. Despite the special preparation aimed at total exfoliation, some of the flakes were not completely separated. It is visible in the middle area of Fig. 6, where (based on the previous conclusion) it is supposed that the number of layers equals 3-4.

We are aware that the analysis of the structure of reduced graphene oxide is not sufficient for a full material description, but based on our previous research, we know that it is in correlation with its properties. For this reason, the presented research results are also important. Currently, investigations on the detailed properties are underway.

In summary, tested reduced graphene oxide is an incompletely reduced material that has not been completely exfoliated. The surface of various sizes is wrinkled and takes on irregular shapes. The single layer is 4-5 nm thick. This material can be used in various ways, for example in lasers [14] or in the aforementioned photodetectors [6].

This work was partially financed by:

- a statutory activity subsidy from the Polish Ministry of Science and Higher Education for the Institute for Chemical Processing of Coal (11.15.024);

- a statutory activity subsidy from the Polish Ministry of Science and Higher Education for the Silesian University of Technology / Faculty of Electrical Engineering / Department of Optoelectronics: BK263/RE4/2020.

\section{References}

[1] X. Peng, Y. Wu, N. Chen, Z. Zhu, J. Liu, H. Wang, Thin Solid Films 692, 137626 (2019).

[2] L. Guo, Y.-W. Hao, P.-L. Li, J.-F. Song, R.-Z. Yang, X.-Y. Fu, S.Y. Xie, J. Zhao, Y.-L. Zhang, Sci. Rep. 8, 1 (2018).

[3] Y.S. Milovanov, V.A. Skryshevsky, O.M. Slobodian, D.O. Pustovyi, X.Tang, J.-P. Raskin, A.N. Nazarov, IEEE 39th Int. Conf. Electron. Nanotechnology, ELNANO 2019 - Proc. 8783946.

[4] M. Reddeppa, B.-G. Park, M.-D. Kim, K.R. Peta, N.D. Chinh, D. Kim, S.-G. Kim, G. Murali, Sensors Actuators B. Chem. 264 , 353 (2018).

[5] W.L. Xu, C. Ding, M.-S. Niu, X.-Y. Yang, F. Zheng, J. Xiao, M. Zheng, X.-T. Hao, Org. Electron. 81, 105663 (2020).

[6] K. Sarkar, M. Hossain, P. Devi, K.D.M. Rao, P. Kumar, Adv. Mater. Interfaces 6, 20 (2019).

[7] S. Pei, H.M. Cheng, Carbon 50, 9 (2012).

[8] R. Muzyka, S. Drewniak, T. Pustelny, M. Chrubasik, G. Gryglewicz, Materials 11, 7 (2018).

[9] M.-H. Tran, H. K. Jeong, New Phys. Sae Mulli 63, 2 (2013).

[10]M.-H. Tran, C.-S. Yang, S. Yang, I.-J. Kim, H. K. Jeong, Curr. Appl. Phys. 14, S.1 (2014).

[11]N. Sharma, Y. Jain, M. Kumari, R. Gupta, S.K. Sharma, K. Sachdev, Macromol. Symp. 376, 1 (2017).

[12]M. Wei, L. Qiao, H. Zhang, S. Karakalos, K. Ma, Z. Fu, M.T. Swihart, G. Wu, Electrochim. Acta. 258, 735 (2017).

[13] S. Drewniak, M. Procek, R. Muzyka, T. Pustelny, Sensors 20, 11 (2020).

[14] L. Li, R.-D. Lv, S. -C. Liu, Z. D. Chen, J. Wang, Y.-G. Wang, W. Ren, Chinese Phys. Lett. 35, 11 (2018). 